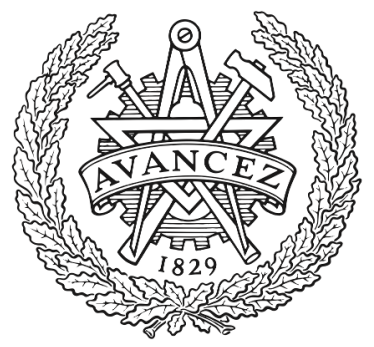

CHALMERS

UNIVERSITY OF TECHNOLOGY

\title{
Nitrogen as the major factor influencing gene expression in Yarrowia lipolytica
}

Downloaded from: https://research.chalmers.se, 2023-04-26 11:07 UTC

Citation for the original published paper (version of record):

Hapeta, P., Kerkhoven, E., Lazar, Z. (2020). Nitrogen as the major factor influencing gene expression in Yarrowia lipolytica. Biotechnology Reports, 27. http://dx.doi.org/10.1016/j.btre.2020.e00521

N.B. When citing this work, cite the original published paper. 


\title{
Nitrogen as the major factor influencing gene expression in Yarrowia lipolytica
}

\author{
Piotr Hapeta ${ }^{\mathrm{a}}$, Eduard J. Kerkhoven ${ }^{\mathrm{b}, \mathrm{c}}$, Zbigniew Lazar $^{\mathrm{a}, *}$ \\ a Department of Biotechnology and Food Microbiology, Wroclaw University of Environmental and Life Sciences, Chelmonskiego 37, 51-630 Wroclaw, Poland \\ ${ }^{\mathrm{b}}$ Department of Biology and Biological Engineering, Division of Systems and Synthetic Biology, Chalmers University of Technology, SE-412 96 Gothenburg, \\ Sweden \\ c Novo Nordisk Foundation Center for Biosustainability, Chalmers University of Technology, SE-412 96 Gothenburg, Sweden
}

\section{A R T I C L E I N F O}

\section{Article history:}

Received 23 June 2020

Received in revised form 29 July 2020

Accepted 25 August 2020

\section{Keywords:}

Yarrowialipolytica

RNAseq

Hexokinase

Nitrogen

Glycerol

\begin{abstract}
A B S T R A C T
Yarrowia lipolytica is an important industrial microorganism used for the production of oleochemicals. The design of effective biotechnological processes with this cell factory requires an in-depth knowledge of its metabolism. Here we present a transcriptomic study of $Y$. lipolytica grown in the presence of glycerol and glucose, and mixture of both at different carbon to nitrogen ratios. It emerged that the transcriptomic landscape of $Y$. lipolytica is more sensitive to the nitrogen availability than to the utilized carbon source, as evidenced by more genes being differentially expressed in lower carbon to nitrogen ratio. Specifically, expression of hexokinase (HXK1) is significantly susceptible to changes in nitrogen concentrations. High HXK1 expression in low nitrogen seems to impact other genes which are implicated in tricarboxylic acid cycle and erythritol biosynthesis. We further show that expression of HXK1 and two genes belonging to the sugar porter family might be controlled by GATA-like zinc-finger proteins.
\end{abstract}

(C) 2020 Published by Elsevier B.V. This is an open access article under the CC BY-NC-ND license (http:// creativecommons.org/licenses/by-nc-nd/4.0/).

\section{Introduction}

Microorganisms are under constant influence of ever-changing nutrient concentrations in their environments, hence sensing and adapting to those changes is crucial for survival. As a result of evolution, several mechanisms helping in precise adaptation of microbial physiology to the environment have developed. Via these mechanisms, i.e. signalling pathways, many microorganisms can directly sense changes in the concentrations of various nutrients, such as carbon and nitrogen sources, and adjust their metabolism to the environmental challenges. The cellular metabolism can be adjusted through fine controlled expression of genes involved in utilization of a given nutrient or its derivatives. These events can be observed in complex, often evolutionarily conserved regulatory processes, such as carbon catabolite repression (CCR) and nitrogen catabolite repression (NCR). Most of our current understanding of CCR and NCR comes from observations of investigating these processes in the model yeast Saccharomyces cerevisiae as reviewed in [1,2], while only few studies have been

\footnotetext{
* Corresponding author at: Department of Biotechnology and Food Microbiology, Wroclaw University of Environmental and Life Sciences, Chelmonskiego 37, 51-630 Wroclaw, Poland.

E-mail address: zbigniew.lazar@upwr.edu.pl (Z. Lazar).
}

devoted to other industrially and environmentally relevant microorganisms such as the oleaginous yeast Yarrowia lipolytica.

The strictly aerobic yeast $Y$. lipolytica is a promising cell factory for production of valuable compounds, such as organic acids [3-5], polyhydroxy alcohols [6,7] and aromas [8]. High protein secretion capacity [9] and FDA awarded GRAS status [10] makes the yeast a potential platform for therapeutic protein production [11]. The most prominent characteristic of $Y$. lipolytica is, however, its ability to accumulate large amounts of intracellular lipids that can reach up to $20 \%$ of cell dry weight in wild-type strains [12]. This trait, together with its ability to use industrial wastes as substrates, e.g. crude glycerol [13], as well as a rapidly expanding range of genetic engineering tools [14-16] render Y. lipolytica an excellent producer of biofuels and other oleochemicals. To design efficient and costeffective bioprocesses with this yeast, utilization of inexpensive and sustainable raw materials combined with a deep, system-level understanding of its metabolism are of great importance.

Y. lipolytica is able to use a plethora of cost-attractive carbon sources. Both, hydrophobic and hydrophilic substrates, such as lipids, glycerol or glucose $[17,18]$ are readily utilized by this yeast. Glycerol is a cheap feedstock for bioprocesses due to its significant amounts generated as by-product of soap and biodiesel industries $[19,20]$. Glucose, on the other hand, is the most abundant monosaccharide found in plant polymers such as starch and cellulose. Unlike the model yeast $S$. cerevisiae, Y. lipolytica utilizes glycerol exhibiting much higher growth rates [21]. Moreover, when 
Table 1

Yeast strains used in this study.

\begin{tabular}{|c|c|c|}
\hline Strain & Genotype & Reference \\
\hline A101 & Wild-type & [24] \\
\hline W29 & Wild-type & {$[10]$} \\
\hline PHY94 & MatA, leu2-270, ura3-302 ${ }^{b}, x p r 2-322, h \times k 1$, glk1, pTEF-HXK1 & [Hapeta et al., in preparation] \\
\hline
\end{tabular}

grown in a medium containing glycerol and glucose, glycerol is consumed first or co-consumed with glucose [22] suggesting an as yet unknown regulatory mechanism(s) controlling this behaviour. An attempt to elucidate the background of this phenomenon using whole transcriptome sequencing under carbon limiting conditions has recently been taken [23]. In the current work, we expand on this by considering the interplay between carbon sources and carbon to nitrogen ratios.

\section{Materials and methods}

\subsection{Yeast strains and media}

The main strain used throughout this study was the wild type $Y$. lipolytica A101 strain [24]. Strains W29 and PHY94 were used for comparisons in gene expression analysis (Table 1 ). The strains were routinely maintained in YPD medium consisting of $10 \mathrm{~g} / \mathrm{L}$ yeast extract, $10 \mathrm{~g} / \mathrm{L}$ peptone, $20 \mathrm{~g} / \mathrm{L}$ glucose or glycerol with optional $10 \mathrm{~g} / \mathrm{L}$ agar (for plates) at $28^{\circ} \mathrm{C}$. For long-term storage the strains were kept at $-80^{\circ} \mathrm{C}$ in $50 \%$ glycerol. Composition of all the minimal media used in this study is listed in Table 2. The YNB (Yeast Nitrogen Base) medium was purchased from Formedium Ltd., Hunstanton, UK. Glycerol and glucose stock solution were of concentration $500 \mathrm{~g} / \mathrm{L}$ and cold-sterilized through $0.22 \mu \mathrm{m}$ membranes. A general representation of the performed experiments and strains used is presented in Fig. 1.

\subsection{Shake-flask cultures}

Cultivations were performed in $250 \mathrm{~mL}$ Erlenmeyer flasks with $50 \mathrm{mLYNB}$ medium. Prepared media were inoculated with biomass to an initial $\mathrm{OD}_{600}$ of 0.5 and incubated at $28^{\circ} \mathrm{C}$ on a rotary shaker with $3 \mathrm{~Hz}$ shaking speed. The samples for biomass and substrate utilization analyses were collected at 0, 6, 10 and $24 \mathrm{~h}$ of culture. In

Table 2

YNB media variants used in this study.

\begin{tabular}{|c|c|c|}
\hline \multirow[t]{3}{*}{ Component } & \multicolumn{2}{|c|}{ Concentration $[\mathrm{g} / \mathrm{L}]$} \\
\hline & \multicolumn{2}{|c|}{ Shake-flasks } \\
\hline & C/N 20 & $\mathrm{C} / \mathrm{N} 40$ \\
\hline YNB & & \\
\hline $\mathrm{NH}_{4} \mathrm{Cl}$ & 4.47 & 2.2 \\
\hline Glucose & & \\
\hline \multirow[t]{3}{*}{ Phosphate buffer pH 6.8} & & \\
\hline & \multicolumn{2}{|c|}{ Bioreactor batch mode } \\
\hline & $\mathrm{C} / \mathrm{N} 20$ & $\mathrm{C} / \mathrm{N} 40$ \\
\hline YNB & & \\
\hline $\mathrm{NH}_{4} \mathrm{Cl}$ & 1.78 & 0.89 \\
\hline $\mathrm{KH}_{2} \mathrm{PO}_{4}$ & & \\
\hline Glycerol & & \\
\hline \multirow[t]{3}{*}{ Glucose } & & \\
\hline & \multicolumn{2}{|c|}{ Bioreactor chemostat mode } \\
\hline & $\mathrm{C} / \mathrm{N} 20$ & $\mathrm{C} / \mathrm{N} 40$ \\
\hline YNB & & \\
\hline $\mathrm{NH}_{4} \mathrm{Cl}$ & 4.47 & 2.2 \\
\hline $\mathrm{KH}_{2} \mathrm{PO}_{4}$ & \multicolumn{2}{|c|}{1} \\
\hline Glycerol & \multicolumn{2}{|c|}{50} \\
\hline Glucose & \multicolumn{2}{|c|}{50} \\
\hline Glycerol + Glucose & \multicolumn{2}{|c|}{$25.2+24.6$} \\
\hline
\end{tabular}

early exponential growth phase $(\mathrm{t}=10 \mathrm{~h}) 1 \mathrm{~mL}$ samples were collected, flash-freezed in liquid nitrogen and kept at $-80{ }^{\circ} \mathrm{C}$ prior to RNA extraction. Experiments were performed in triplicates.

\subsection{Bioreactor cultures}

The batch bioreactor cultures were performed in Biostat B Plus fermenters (Sartorius-Stedim, Germany) under following conditions: the working volume of $1500 \mathrm{~mL}$, the temperature of $28{ }^{\circ} \mathrm{C}$, the stirring rate of $10 \mathrm{~Hz}$ and the aeration of $0.6 \mathrm{vvm}$ (vessel volume per minute). $\mathrm{pH}$ was automatically maintained at $\mathrm{pH} 6.8$ by addition of $40 \%(\mathrm{w} / \mathrm{v}) \mathrm{KOH}$. Initial $\mathrm{OD}_{600}$ was set to 0.5 . The experiments were performed in biological duplicates.

\subsection{Chemostat cultivations}

The chemostat cultivations were carried out in Biostat B Plus fermenters (Sartorius-Stedim, Germany) under following conditions: the working volume of $750 \mathrm{~mL}$, the temperature of $28^{\circ} \mathrm{C}$, the stirring rate of $10 \mathrm{~Hz}$ and the aeration of $0.6 \mathrm{vvm}$ (volume of air per volume of liquid per minute). $\mathrm{pH}$ was automatically maintained at 6.8 by addition of $40 \%(\mathrm{w} / \mathrm{v}) \mathrm{KOH}$. The dilution rate was set at $0.05 /$ h. The process was held until the steady state (7-12 media exchanges, depending on applied carbon source), defined as constant biomass and constant remaining substrate concentration in the post-fermentation medium for at least $48 \mathrm{~h}$ were achieved. At steady states $10 \mathrm{~mL}$ samples were collected, flash-freezed in liquid nitrogen and kept at $-80{ }^{\circ} \mathrm{C}$ prior to RNA extraction. Each culture variant was carried out in biological duplicate.

\subsection{RNA extraction}

The RNA for transcriptome sequencing was obtained by disrupting the cells using Mikro-Dismembrator $U$ ball mill (Sartorius AG, Göttingen, Germany) and metal beads, followed by extraction using RNeasy Mini Kit (Qiagen, Hilden, Germany) according to the manufacturers' protocol. RNA for qRT-PCR were extracted using Total RNA Mini kit (A\&A Biotechnology, Gdynia, Poland) according to the provided protocol. In both cases, extracted RNA was checked for quality using Biochrom WPA Biowave DNA spectrophotometer (Biochrom Ltd., Cambridge, UK).

\subsection{Quantitative real-time PCR}

Extracted RNA samples were treated with DNase (A\&A Biotechnology, Gdynia, Poland) and reverse transcribed to cDNA using Maxima First Strand cDNA Synthesis Kit for RT-qPCR (Thermo Scientific). The obtained cDNA samples were then used for qPCR reaction using Maxima SYBR Green qPCR Master Mix (Thermo Scientific) and primers listed in Table S1 on the PCRmax Eco 48 thermal cycler (Illumina, San Diego, CA). Expression of genes was standardized to the expression of actin (YlACT1, YALIOD08272g) gene.

\subsection{RNA sequencing}

The RNA samples from chemostat cultivations were sequenced by Novogene (Beijing, China) using HiSeq 4000 next-generation 


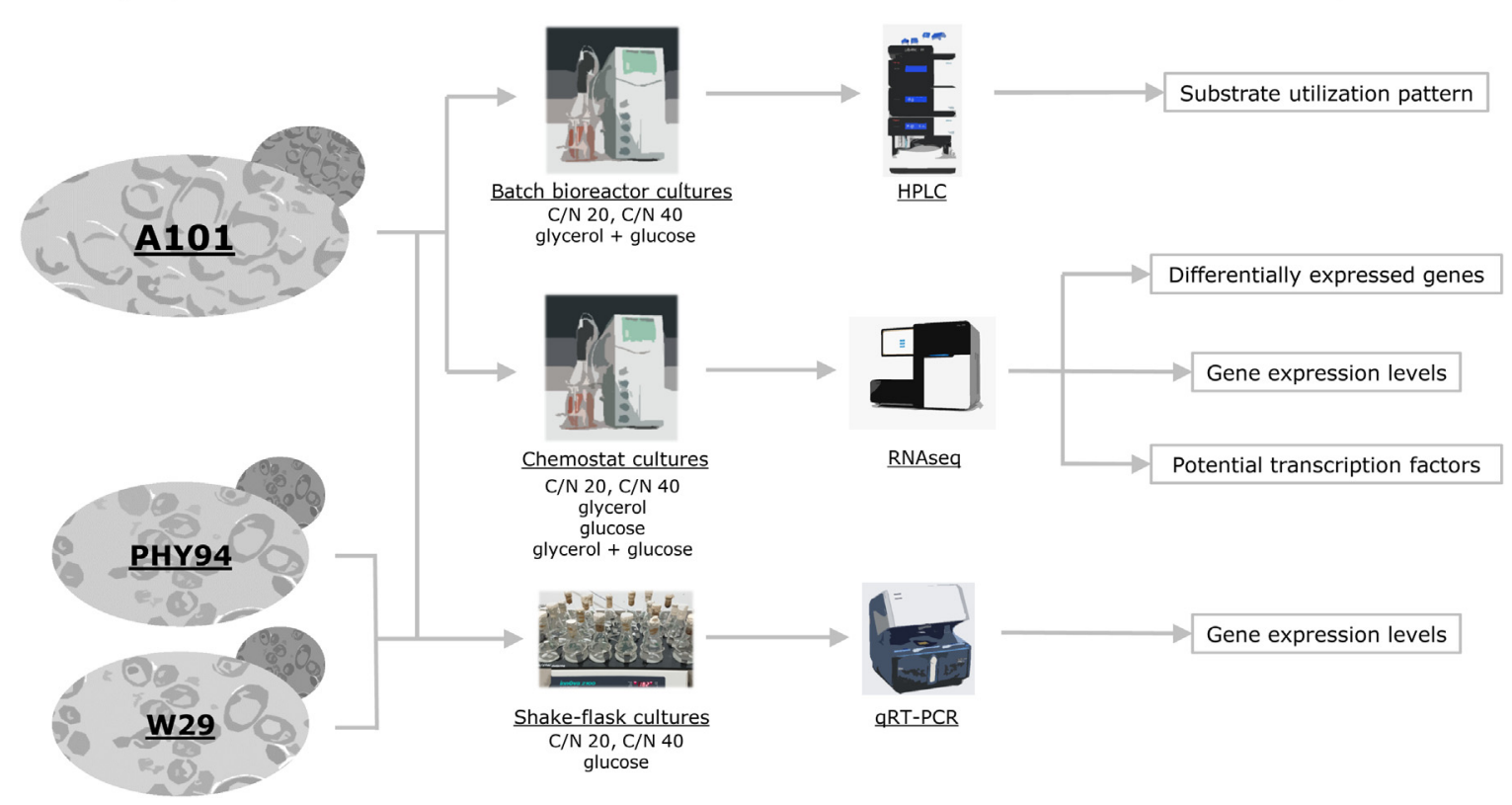

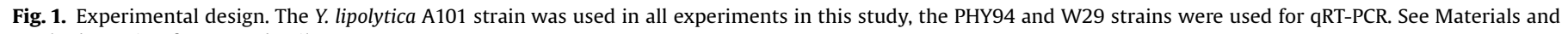
methods section for more details.

sequencer (Illumina, San-Diego, CA) in paired end mode. The obtained reads were of length $150 \mathrm{bp}$.

\subsection{Bioinformatics analysis}

The RNAseq reads were checked for quality using FastQC 0.11.9 [25] and the 12 bp adapter regions were trimmed by Trimmomatic 0.39 [26]. Subsequently, the reads were mapped to Y. lipolytica CLIB122 genome (GenBank assembly identifier: GCA_000002525.1) using STAR Aligner 2.7.2b [27] and quantified with the featureCounts of Subread package 2.0.0 [28]. The count table was used to identify differentially expressed genes with DESeq package [29]. In order to determine potential transcription factors controlling gene expression in Y. lipolytica, $1 \mathrm{~kb}$ sequences up-stream of chosen genes were retrieved from NCBI database. The YALIO gene identifiers were used as an input for YEASTRACT + database [30]. The pathways were reconstituted using KEGG pathway database [31].

\subsection{Analytical methods}

Substrate utilization was determined using Dionex UltiMate 3000 HPLC instrument (Dionex-ThermoFisher, UK) equipped with a Carbohydrate $\mathrm{H}+$ column (Thermo Scientific, Waltham, MA) coupled to an UV ( $\lambda=210 \mathrm{~nm})$ and RI (Shodex, Ogimachi, Japan) detectors according to standards. The column was eluted with 25 mmol trifluoroacetic acid at $65{ }^{\circ} \mathrm{C}$ and a flow rate of $0.6 \mathrm{~mL} / \mathrm{min}$.

The growth was monitored by measuring optical density at 600 nm using SmartSpec Plus spectrophotometer (Biorad, Hercules, CA). Additionally, the dry biomass during bioreactor cultures was determined gravimetrically after cells being filtered through 0.22 $\mu \mathrm{m}$ membranes and dried at $105^{\circ} \mathrm{C}$ using laboratory balance with moisture analyzer (RADWAG, Radom, Poland).

\subsection{Calculations}

The biomass yield was calculated as follows:

$$
\frac{Y x}{S}=-\frac{[X f]-[X i]}{[S f]-[S i]}
$$

Where:

Yx/s - biomass yield coefficient [g/L]

[Xi], [Xf] - initial and final biomass concentration, respectively [g/L]

[Si], [Sf] - initial and final biomass concentration, respectively

Substrate utilization and specific substrate utilization rates were calculated for linear utilization curves using following equations:

$Q=\frac{[S b]-[S a]}{t b-t a}$

$q=\frac{Q}{X a v g}$

Where:

$\mathrm{Q}$ - substrate utilization rate $[\mathrm{g} / \mathrm{L} / \mathrm{h}]$

$\mathrm{q}$ - specific substrate utilization rate $[\mathrm{g} / \mathrm{g} / \mathrm{h}]$

[Sa], [Sb] - substrate concentration at the beginning and end of linear substrate utilization, respectively $[\mathrm{g} / \mathrm{L}]$

ta, tb - time of culture at the beginning and end of linear substrate utilization, respectively [h]

Xavg - average of biomass concentration at ta and tb

\section{Results}

\subsection{Substrate utilization pattern}

In oleaginous yeasts such as Y. lipolytica, a low availability of nitrogen in the cultivation medium activates lipid accumulation and/or citric acid secretion [32,33], while more nitrogen promotes cells division rapidly generating biomass [34,35]. In this study we aimed to investigate how two readily available substrates, namely glycerol and glucose, are utilized at different carbon to nitrogen ratios $(\mathrm{C} / \mathrm{N})$. Therefore, we performed bioreactor batch cultures of a wild-type $Y$. lipolytica A101 strain at two different $\mathrm{C} / \mathrm{N}$ ratios (20 and 40) in a minimal YNB medium with a mixture of glucose and glycerol. In both experiments, nitrogen availability had no effect on 

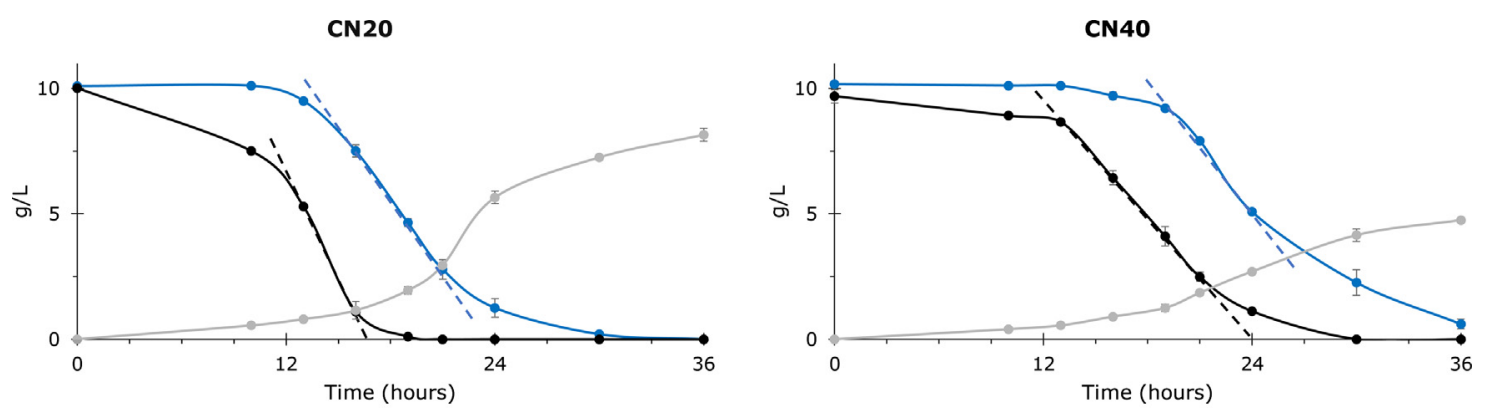

$\rightarrow$ Glucose $\rightarrow$ Glycerol $\multimap$ Biomass

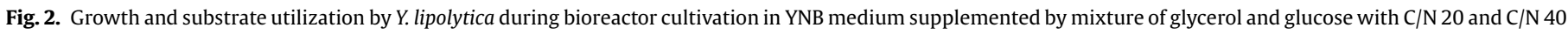

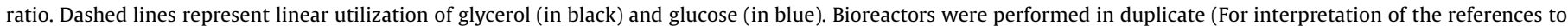
colour in this figure legend, the reader is referred to the web version of this article).

Table 3

Growth parameters of $Y$. lipolytica growing in YNB medium with a mixture of glycerol and glucose at $\mathrm{C} / \mathrm{N} 20$ and $\mathrm{C} / \mathrm{N} 40$ ratio.

\begin{tabular}{ccccccc}
\hline & $\begin{array}{c}\mathrm{Y}_{\mathrm{X} / \mathrm{S}} \\
{[\mathrm{g} / \mathrm{g}]}\end{array}$ & $\begin{array}{c}\mathrm{Q}_{\text {gly }} \\
{[\mathrm{g} / \mathrm{L} / \mathrm{h}]}\end{array}$ & $\begin{array}{c}\text { qgly } \\
{[\mathrm{g} / \mathrm{g} / \mathrm{h}]}\end{array}$ & $\begin{array}{c}\mathrm{Q}_{\mathrm{glc}} \\
{[\mathrm{g} / \mathrm{L} / \mathrm{h}]}\end{array}$ & $\begin{array}{c}\mathrm{q}_{\text {glc }} \\
{[\mathrm{g} / \mathrm{g} / \mathrm{h}]}\end{array}$ & qgly $/ \mathrm{q}_{\text {glc }}$ \\
\hline CN20 & 0.40 & 1.39 & 1.42 & 0.94 & 0.46 & 3.09 \\
CN40 & 0.25 & 0.77 & 0.64 & 0.83 & 0.42 & 1.52 \\
\hline
\end{tabular}

the substrate utilization pattern - glycerol was used prior to glucose (Fig. 2). However, at both $\mathrm{C} / \mathrm{N}$ ratios, slow glucose utilization could be seen when glycerol was above $5 \mathrm{~g} / \mathrm{L}$. Below that concentration glucose consumption accelerated substantially regardless $\mathrm{C} / \mathrm{N}$. As expected, more biomass was generated in higher nitrogen concentration (C/N 20) as reflected by the yield coefficient values $\left(\mathrm{Y}_{\mathrm{X} / \mathrm{S}}\right.$, Table 3$)$. Both glycerol and glucose utilization rates $(\mathrm{Q})$ for linear utilization curves were higher at $\mathrm{C} / \mathrm{N} 20$ than at $\mathrm{C} / \mathrm{N} 40$ (Fig. 2; Table 3). Additionally, a steep slope of glycerol utilization at $\mathrm{C} / \mathrm{N} 20$ was observed and the $\mathrm{q}_{\mathrm{gly}}$ was ca. 2.2-fold higher than at C/ N 40.

3.2. Transcriptional changes during growth on glucose, glycerol and a mixture of glucose and glycerol at C/N 20 and $C / N 40$

To elucidate the effect of $\mathrm{C} / \mathrm{N}$ ratio on carbon utilization, wildtype Y. lipolytica A101 strain was cultivated in bioreactors under chemostat conditions where nitrogen was the growth limiting nutrient at the selected $\mathrm{C} / \mathrm{N}$ ratios. In all experimental variants the cells were grown at the same dilution rate (specific growth rate) of $0.05 / h$. This dilution rate was selected as it has previously been shown as optimal for directing carbon flux towards lipid accumulation [36]. Throughout the cultivations, samples were taken for analysis of $\mathrm{OD}_{600}$, substrate and biomass concentrations (Fig. S1). At steady state, defined as a constant biomass and substrate concentration in the culture medium, samples were rapidly taken for RNA extraction and subsequent RNA sequencing and data analysis.

The normalized counts from RNA sequencing were used for quantification of the transcript levels. The purpose of this analysis was to assess the impact of two factors on the transcriptomic landscape of $Y$. lipolytica, where the first factor was the carbon source and the second - nitrogen availability (C/N 20 and C/N 40). Three carbon source conditions were analyzed - glycerol, glucose and an equimolar blend of glucose and glycerol. The glycerol culture was set as a reference condition. The $\mathrm{p} \leq 0.05$ and $\log 2$ (fold-change) $\geq 1.5$ were used as cut-offs. The results showed, that at $\mathrm{C} / \mathrm{N} 20$ ratio in YNB glucose medium, 30 genes were up- and 50 were downregulated compared to the glycerol cultured cells (Fig. 3A). At C/N 40 ratio, 21 genes were subjected of up- and 12 of downregulation by glucose. The presence of glycerol in the mixed cultures at C/N 20 caused 35 genes to be upregulated ( 5 more than in the glucose culture) and 38 to be downregulated (12 less than in glucose culture), while at C/N 40 only 2 genes were differentially expressed, from which both were downregulated. The complete list of differentially expressed genes is available in supplementary materials (File $\mathrm{S} 1$ ).

Next, we were interested to identify those genes that were differentially expressed on both glucose and a mixture of glucose

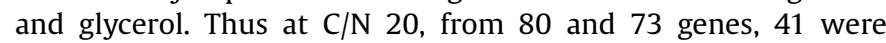
common and differentially expressed due to the presence of glucose (Fig. 3B). In this group, the YHT1 (hexose transporter) and ALK1 (n-alkane inducible cytochrome P450) were found. Similar comparison at $\mathrm{C} / \mathrm{N} 40$ revealed no overlapping genes.

Subsequently, the impact of nitrogen availability on gene expression was assessed by comparing glucose and mixed cultures at $\mathrm{C} / \mathrm{N} 20$ and 40. The comparison of glucose cultures shown 3 genes to be differentially expressed at both C/N 20 and 40 (Fig. 3C). When mixed cultures were taken for comparison, the 2 downregulated genes at $\mathrm{C} / \mathrm{N} 40$ were also present in the group of 73 differentially expressed genes at C/N 20 (Fig. 3C). In both subsets, the YHT4 gene encoding another hexose transporter was found.

By comparing the downregulated genes at C/N 20 (see Fig. 3A, blue bars), it transpired that 57 genes were negatively affected by glucose, of which 31 genes were downregulated in both mixed and glucose-only cultures (Fig. 4A). Among these 31 consistently downregulated genes (Supplementary File S1) was $A B C 3$. On the other hand, there were 8 genes upregulated in both carbon source conditions (Fig. 4B, File S1), among which most notably YHT1 and ALK1. The YHT4 and CIT1 (mitochondrial 2-methylcitrate synthase) genes were among those upregulated by glucose alone and the group of 27 genes in which ALK2 (n-alkane inducible cytochrome P454) and LIP8 (triacylglycerol lipase precursor) genes were present, were upregulated in the mixed culture.

At $\mathrm{C} / \mathrm{N} \mathrm{40,}$, only the YHT4 gene was downregulated in both carbon sources (Fig. 4C), while no genes were upregulated in mixed cultures, leaving a set of 21 genes upregulated in glucose-only cultures, including ALK2 (Fig. 4D).

\subsection{Targeted-transcriptome analysis reveals major impact of nitrogen on gene expression}

To gain a more detailed understanding on the transcriptomic behaviors, a targeted expression analysis was carried out, for which groups of genes responsible for relevant biological processes were selected. The expression levels of genes encoding for sugar and glycerol transport, kinases, glycerol metabolism, the tricarboxylic acid cycle and erythritol metabolism are depicted in Fig. 5. 


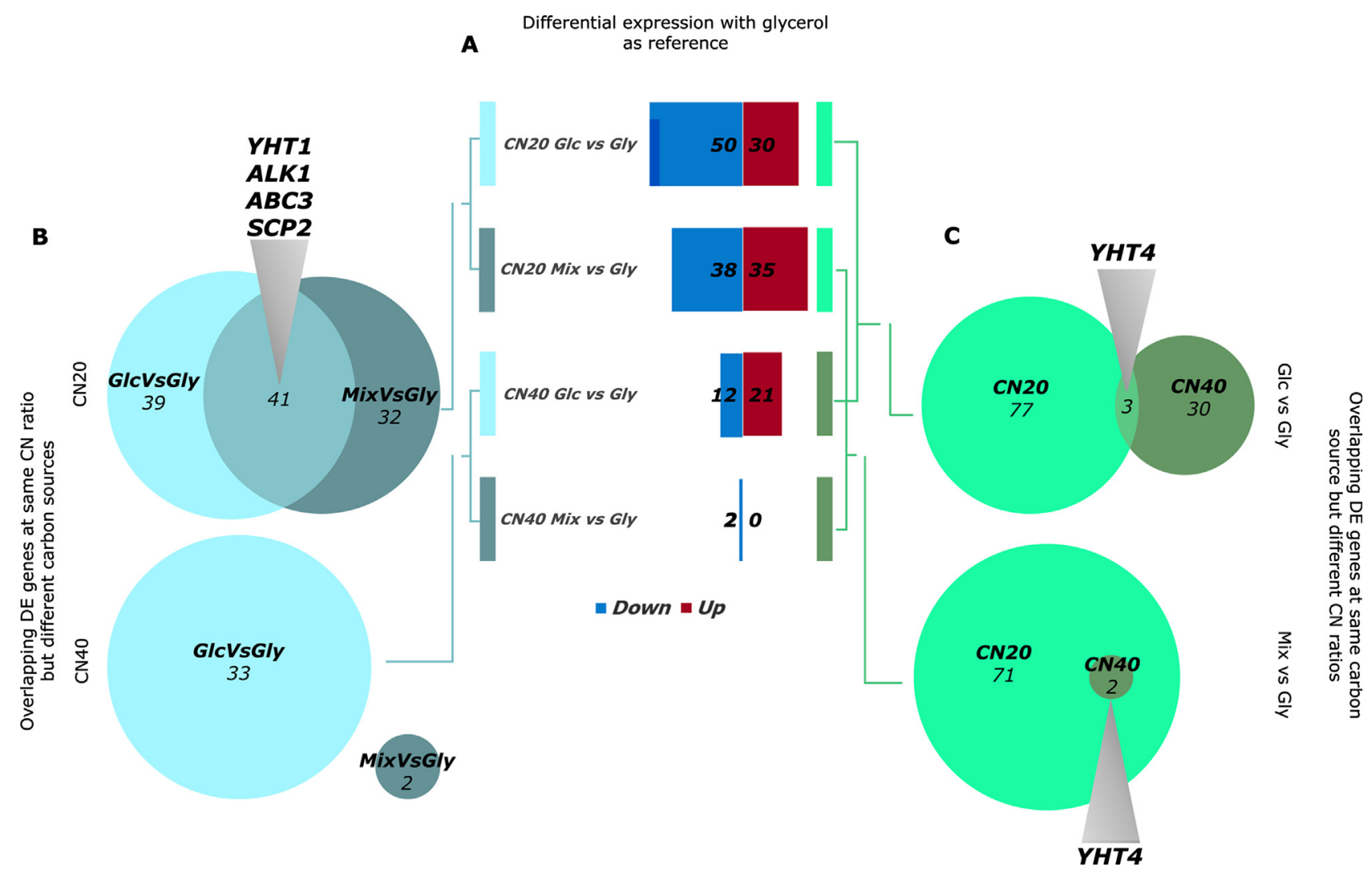

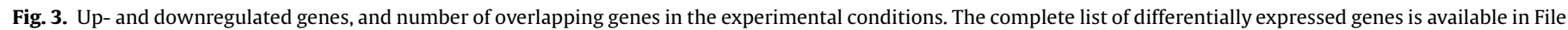
S1 (Supplementary Materials).

A first step in the metabolism of glucose and glycerol is their internalization through the plasma membrane. The most highly expressed known hexose transporters in all conditions were YHT1 and YHT4. Five other genes from the sugar porter family, namely YALIOB21230g, YALIOF6776g, YALIOF18084g and YALIOF23903g showed similar expression pattern to YHT1 and YHT4, however, the expression levels were much lower than for YHT1 (Fig. 5A). Regarding glycerol transport, the Y. lipolytica FPS1 (YALIOF00462g) aquaglyceroporin homologue showed almost constant, high expression levels across all conditions but with an increased expression on glycerol at $\mathrm{C} / \mathrm{N} 40$.

The consequence of glycerol and glucose uptake into the cell is their phosphorylation by relevant kinases, that allows their incorporation into the central carbon metabolism. The main glycerol phosphorylating protein in $Y$. lipolytica is a YALIOF00484g encoding glycerol kinase Gut1 which expression was higher at $\mathrm{C} / \mathrm{N} 40$ and the highest in cells cultivated on glycerol (Fig. 5B). The GUT1 gene is an element of the glycerol-3phosphate pathway, which consist of two other genes, GUT2 and GPD1. Both of the later genes showed rather similar expression profiles. It has been proposed that $Y$. lipolytica has a secondary glycerol dissimilation pathway $[23,37]$. According to the current state of knowledge, this still dubious DHA pathway could be potentially encoded by 10 genes of which two (DAK2, GCY15) showed higher expression than the others in the present study (Fig. 5B).

In Y. lipolytica glucose is phosphorylated by either glucokinase Glk1 or a hexokinase $H x k 1$. While expression levels of GLK1 remained relatively constant across all conditions, the HXK1 gene exhibited drastically increased expression at $\mathrm{C} / \mathrm{N} 40$ compared to at $\mathrm{C} / \mathrm{N} \mathrm{20}$, appearing as the strongest signal of all analyzed genes in this work (Fig. 5C). Additionally, the YALIOD16357g gene encoding phosphofructokinase showed a more moderately increased expression at $\mathrm{C} / \mathrm{N} 40$ with the highest expression in the presence of glucose. These changes could support a higher flux in glycolysis when nitrogen is less abundant. We were also interested to investigate the expression levels of Y. lipolytica SNF1 and MIG1 homologues, which in S. cerevisiae form the core of the SNF1/MIG1 pathway: components of the glucose repression mechanisms. The expression of SNF1 was not dependent on the carbon source, however slightly higher expression was observed when cells were grown in lower nitrogen concentration (Fig. 5D).

Particularly increased expression was observed for YALIOC24101g gene encoding pyruvate carboxylase PYC1 at $\mathrm{C} / \mathrm{N}$ 40 (Fig. 5E). Notably, expression of ACO1, encoding aconitase, was the highest at $\mathrm{C} / \mathrm{N} 40$ with a particularly strong signal on glucose, while CIT2 (citrate synthase) showed over 3-fold lower expression on glycerol than on glucose at $\mathrm{C} / \mathrm{N} 40$. The genes encoding enzymes further in the TCA cycle, such as those responsible for succinate to fumarate conversion (succinate dehydrogenase complex, $S D H$ ) showed in general low expression compared to the other TCA genes, however, increased expression was observed during cultivation on glucose at C/N 40 (Fig. 5E).

$Y$. lipolytica is also well known for its overproduction of erythritol, therefore, we checked expression level of genes encoding erythritol biosynthesis pathway (Fig. 5F). Four genes from this pathway revealed significant differences in expression on glucose at C/N 20 and C/N 40. These genes, namely TAL1, GCY15, ARA12 and GRE3 (also annotated to the DHA pathway), encoding transaldolase and three erythrose reductases, respectively, showed lower expression when less nitrogen was available. A similar pattern was observed for genes from two other pathways - DAK2 associated with glycerol metabolism, as well as IDH1, IDH2 and ICL1 involved in the tricarboxylic acid cycle (TCA). 
A
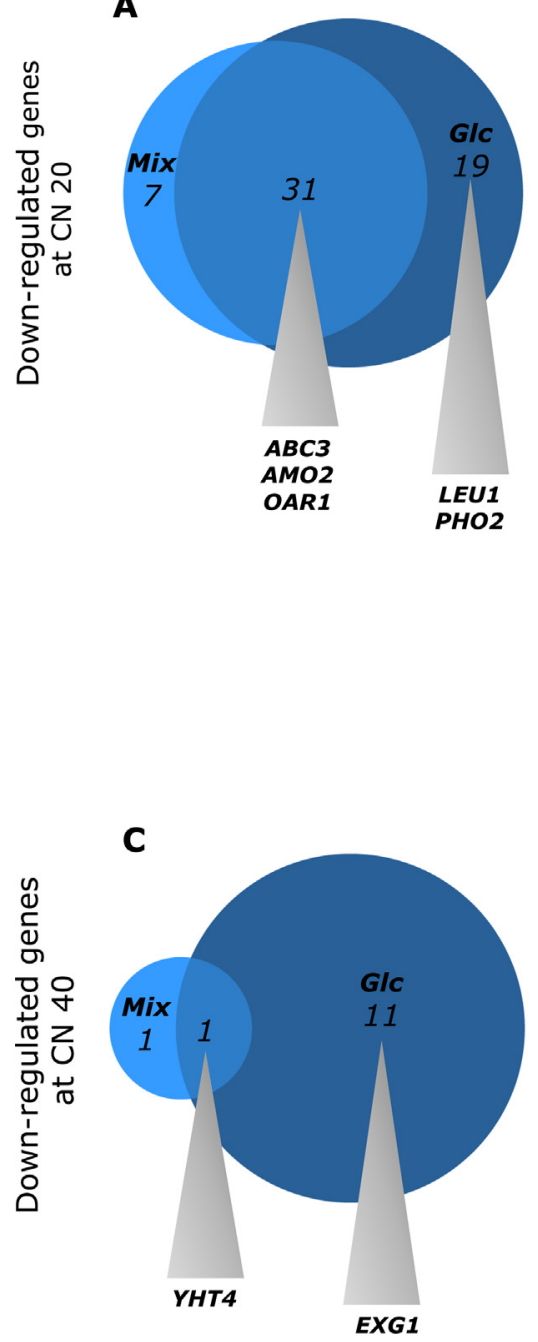

B

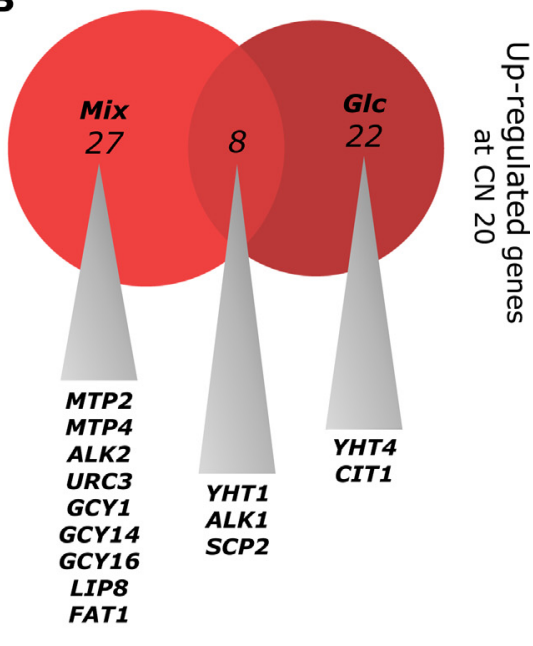

CN4O Mix vs Gly

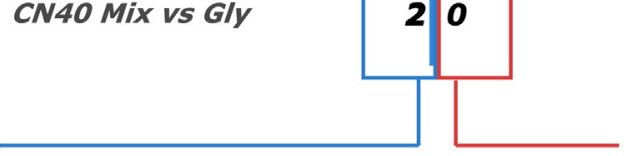

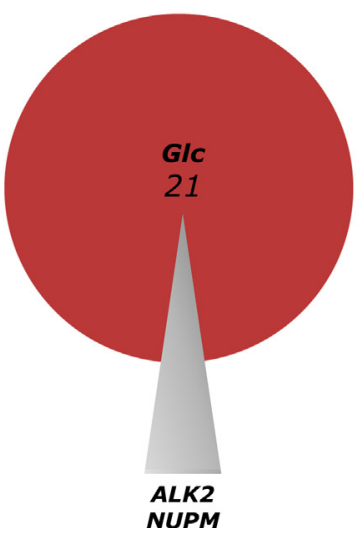

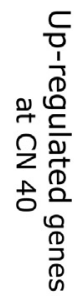

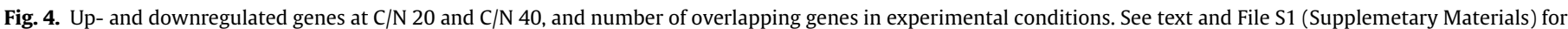
more details.

\subsection{Influence of hexokinase on gene expression levels}

The drastic differences in HXK1 expression could have regulatory effect on other genes, we therefore searched for genes with a correlating expression profiles. In other words, we reasoned that strong HXK1 expression might influence expression of several genes by an unknown mechanism. The targeted transcriptome analysis described above revealed a set of 8 genes with high expression at $\mathrm{C} / \mathrm{N} 20$ and low at $\mathrm{C} / \mathrm{N} 40$ (Fig. 6A). To test our hypothesis that hexokinase plays such role we designed an experiment with batch cultures of (i) Y. lipolytica A101, (ii) a wild-type W29 as control strain; and (iii) a HXK1 overexpressing PHY94 strain [Hapeta et al., in preparation]. All cultures were performed in flasks with glucose media at either $\mathrm{C} / \mathrm{N} 20$ or $\mathrm{C} / \mathrm{N} 40$. The data for W29 are included because the PHY94 strain is a W29 derivative. Samples for analysis were taken from early exponential growth phase $(\mathrm{t}=10 \mathrm{~h})$ and subjected to RNA extraction, followed by qRT-PCR analysis. We confirmed the expression level of HXK1 obtained from RNASeq analysis (Fig. 6B) as well as the levels of DAK2, GCY15, GRE3, TAL1, ARA12, IDH1, IDH2 and ICL1 (Fig. 6C). The relative expressions of these genes in A101 strain were similar to those obtained from RNAseq, while the pattern was also observed for the W29 strain. From the obtained data transpires that overexpression of $H X K 1$ correlates with an increase of GCY15, GRE3,
IDH1 and IDH2 expression at C/N 40. In contrary, comparing the PHY94 (overexpressing HXK1) to the wild-type strains, the levels of DAK2, ARA12 and IDH2 seems to be decreased in $\mathrm{C} / \mathrm{N} 20$. Interestingly, TAL1 expression was lower at $\mathrm{C} / \mathrm{N} 20$ and higher at $\mathrm{C} / \mathrm{N} 40$ when HXK1 was overexpressed, while the ICL1 remained almost unchanged. The results show a correlation of HXK1 expression with the transcript levels of the analyzed genes, suggesting a role of hexokinase in the regulation of these genes.

\subsection{Expression of hexokinase and two sugar porters might be controlled by zinc finger proteins in Y.lipolytica}

Genes with similar expression patterns potentially often share common transcription factors binding to the promoter regions, thereby controlling their expressions. The targeted transcriptome analysis allowed identification of three genes with similar expression profiles, namely HXK1 and two genes from the sugar porter family - YALIOC04730g and YALIOD01111g (Fig. 7). Analyzing a 1000 bp sequences upstream to the start codons of these genes as an input for YEASTRACT + database [30] two potential transcription factors have been identified, namely YALIOC22682p and YALIOF17886p. The primary structure of YALIOC22682p shows some similarities with a $S$. cerevisiae Gzf3 transcriptional repressor, while the sequence of YALIOF17886p is similar to S. cerevisiae Gat1 

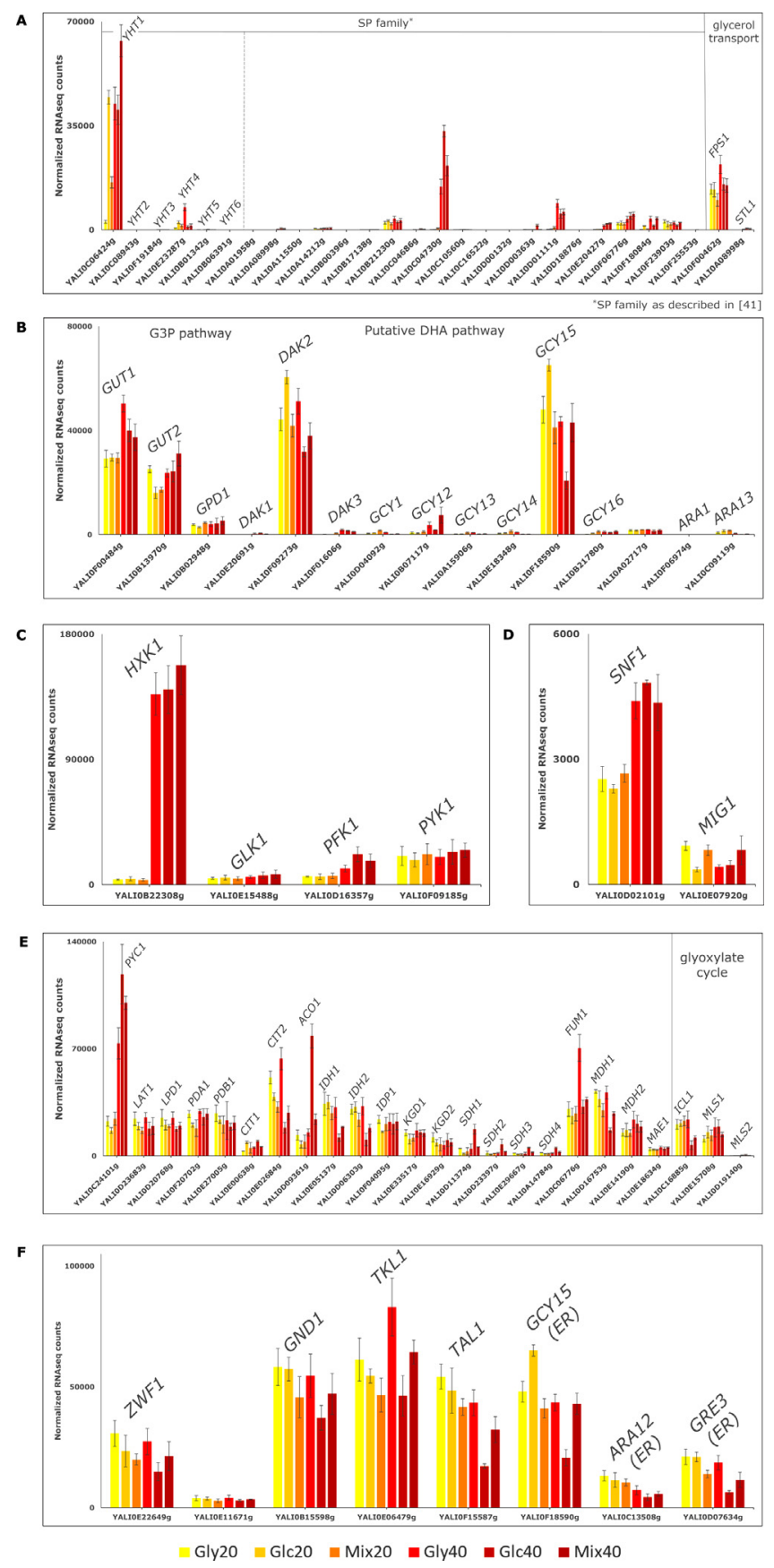

Fig. 5. Targeted transcriptome analysis. A - transporter genes; B - glycerol metabolism genes; C- kinases; D - SNF1 and MIG1; E - tricarboxylic acid cycle genes; $\mathrm{F}$ - erythritol biosynthesis genes.

transcription factor for nitrogen regulation. In fact both Gzf3 and Gat1 are GATA zinc finger proteins acting as transcription factors for the nitrogen catabolite repression genes. These two transcription factors in $S$. cerevisiae are the elements of the GATA gene regulatory network and recognize the same core motif in the promoter regions of their gene targets. All three promoter sequences analyzed here contain such motifs (Fig. S2), what indicates that expression of HXK1, YALIOC04730 $\mathrm{g}$ and YALIOD01111 $\mathrm{g}$ genes could be controlled by Gzf3 and/or Gat1 as indicated by YEASTRACT + database search.

\section{Discussion}

The present study focused on elucidating the molecular background of glucose and glycerol utilization patterns in the important industrial yeast $Y$. lipolytica and the impact of carbon to nitrogen ratio on its gene expression. One of the unique properties of this yeast is the preferential use of glycerol over glucose [22], a phenomenon described only for one other organism, the haloarchaeon Haloferax volcanii [38]. As in this latter microorganism a glycerol catabolite repression has been described, we hypothesized that a similar mechanism exists in Y. lipolytica as it has been reported that glycerol represses n-alkane utilization [39]. While some wild-type $Y$. lipolytica strains, show a co-utilization of glycerol and glucose, including the W29 and H222 strains and the A101 strain presented here, other wild-type strains use glucose only when glycerol is completely depleted [23]. In our study a sequential utilization of these two carbon sources was observed, however, glucose uptake began when glycerol concentration dropped below $5 \mathrm{~g} / \mathrm{L}$. This suggests a mechanism which senses glycerol (or carbon source in general) in the environment and allows for an efficient cell reprograming for the metabolism of other, less preferable carbon sources such as glucose. The analyzed $\mathrm{C} / \mathrm{N}$ ratios did not influence the substrate utilization pattern but varying uptake rates of both substrates at tested $\mathrm{C} / \mathrm{N}$ ratios were observed. Moreover, at $\mathrm{C} / \mathrm{N} 20$ a sequential utilization of substrates occurred while at $\mathrm{C} / \mathrm{N} 40$ the substrates were co-utilized. This is in concert with other studies at different culture modes, in which glycerol was also used prior to glucose [22,23]. It seems, that nitrogen availability does not influence the unique pattern of substrate utilization in Y. lipolytica, however, there are some variations in a mode of its utilization (co-utilization or sequential). We hypothesize, that this phenomenon might be connected to the fact, that in higher nitrogen concentrations (C/N 20) the cellular machinery of $Y$. lipolytica is set for biomass production, while when nitrogen becomes scarce ( $\mathrm{C} / \mathrm{N} 40)$ the cells begin to store available carbon in storage molecules such as triacylglycerols (TAG) and glycogen. This could also explain slightly higher specific glucose

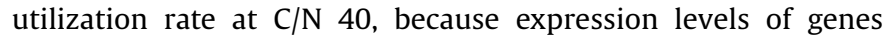
involved in TAG and glycogen biosynthesis are higher at $\mathrm{C} / \mathrm{N} 40$ than at C/N 20 (Fig. S3). Interestingly, this expression pattern was also observed for genes responsible for lipid mobilization and degradation (Fig. S3). Additionally, it has been previously reported that deletion of the glycogen synthase, a key enzyme in glycogen biosynthesis pathway, increases TAG formation in Y. lipolytica [40].

The RNAseq analysis allowed for quantification and identification of differentially expressed genes during growth on glycerol, glucose and a mixture of both substrates at two $\mathrm{C} / \mathrm{N}$ ratios. The number of differentially expressed genes at C/N 20 was higher than at $\mathrm{C} / \mathrm{N} 40$, indicating that nitrogen availability has a major impact on gene expression in the chemostat cultures, regardless carbon source. However, a certain glycerol regulatory effect was observed, as its presence in the medium with glucose caused reduction in the number of downregulated genes at both $\mathrm{C} / \mathrm{N}$ ratios (Fig. 3). In fact, the ALK1 gene implicated in n-alkane utilization was identified as differentially expressed on all carbon sources at C/N 20. Moreover, this gene was upregulated/derepressed by glucose and at the same time downregulated by glycerol (Fig. 4), what confirms previous findings [39]. In almost all tested conditions, the hexose transporters YHT1 or YHT4 were differentially expressed what suggests that glucose transport is particularly susceptible to changes in carbon source quality and nitrogen availability. Further, the YHT4 was upregulated on glucose at $\mathrm{C} / \mathrm{N} 20$ as could be expected by examining the function of its product - a high affinity glucose transport [41]. It is puzzling however, that the same gene was downregulated on glucose at C/N 40 (Fig. 4). 
A

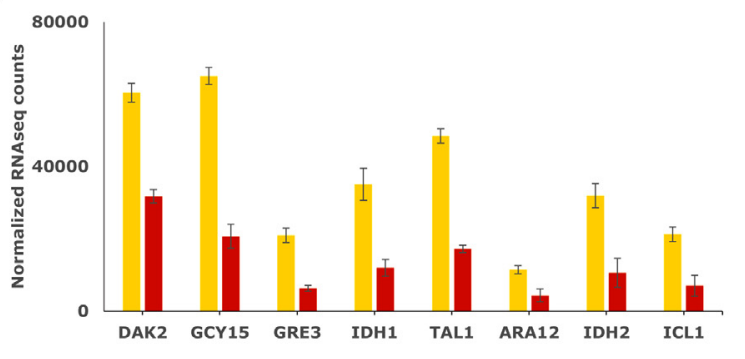

B

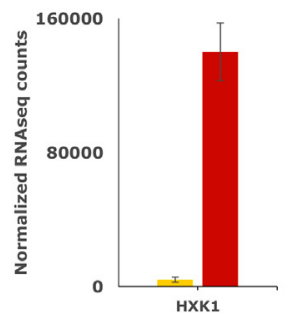

$\square \mathrm{CN} 20 \square \mathrm{CN} 40$

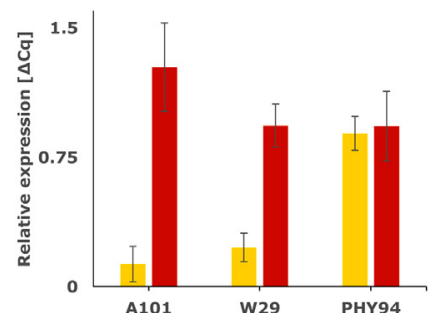

C
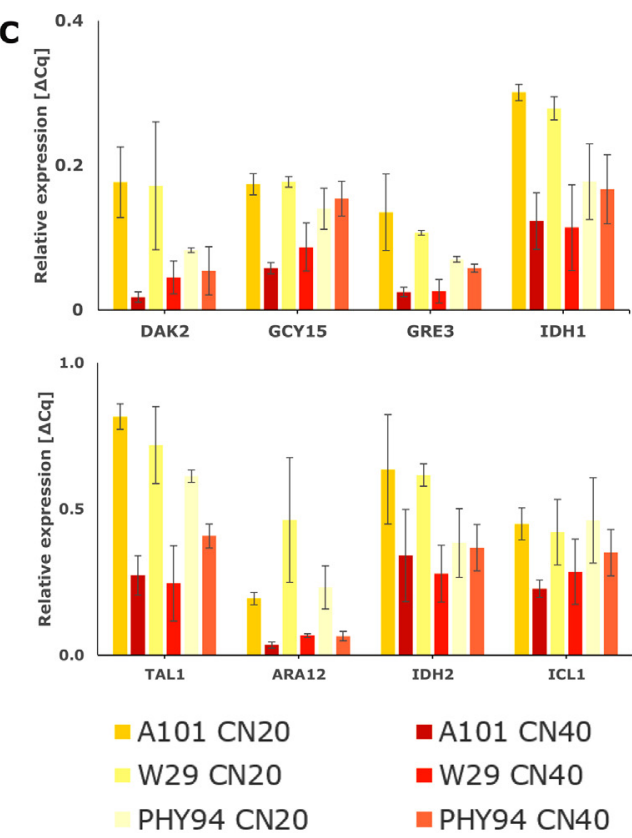

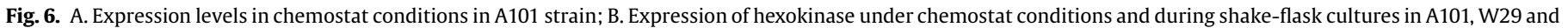
PHY94; C. Expression levels during shake-flask cultivations. For clarity only transcript levels during glucose cultures are shown.

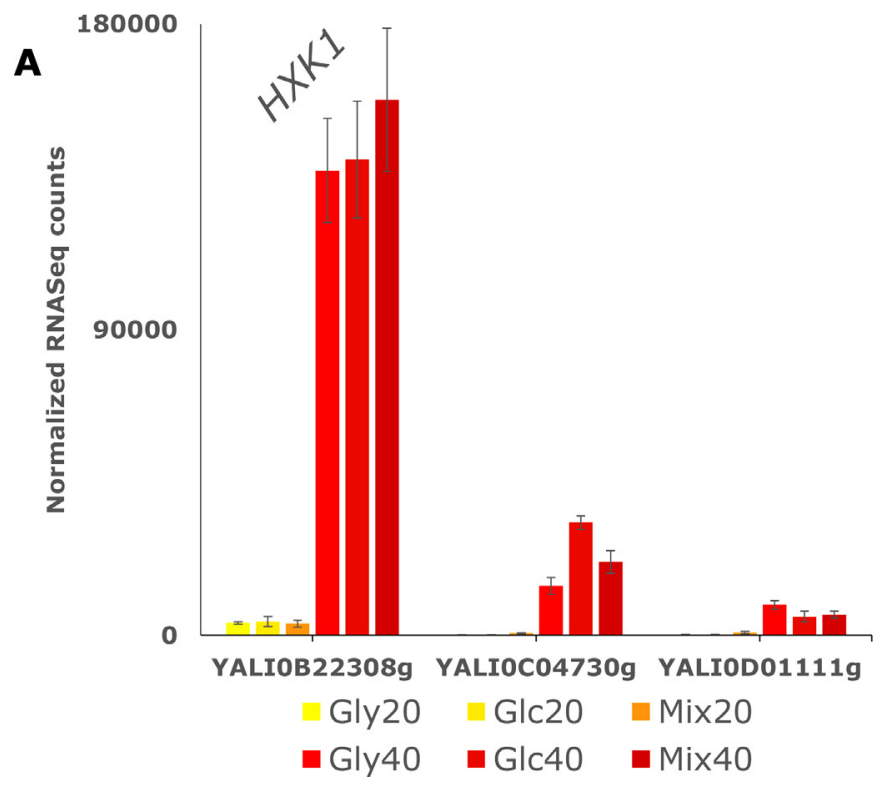

B

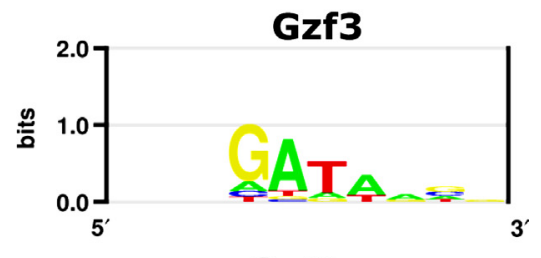

Gat1

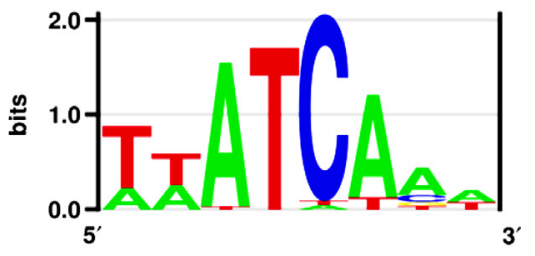

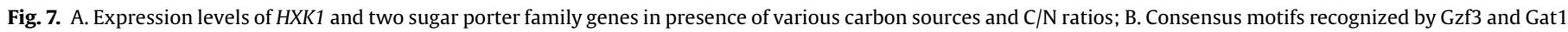
transcription factors.

Recently, a transcriptomic analysis of two Y. lipolytica strains growing in glucose, glycerol and a mixture of both substrates in carbon limiting conditions has been revealed [23]. In their experimental setup, the W29 strain showed 94 differentially expressed genes when cultures on glycerol and glucose were compared, while in the IBT strain 61 genes were identified as differentially expressed. The same comparison in our study showed 80 and 33 genes at C/N 20 and C/N 40, respectively. This indicates that the transcriptomic landscape of $Y$. lipolytica is straindependent and varies widely in different cultivation conditions. Our results show that less changes occur when less nitrogen is available and that its availability has higher impact on gene expression than different carbon sources and further advanced our understanding on the transcriptional changes in various cultivation conditions.

The sugar uptake is not completely resolved in $Y$. lipolytica, as proven by the number of publications on that subject. The most extensive study yet resulted in the identification of 24 proteins belonging to a sugar porter (SP) superfamily, from which 6 (Yht1Yht6) were identified as hexose transporters. Among these, Yht1 and Yht4 are the most important for glucose uptake [41]. The expression levels presented here confirm that YHT1 and YHT4 play a major role in glucose transport, however, their expression was also detected in glycerol cultures, what might indicate that sugar transporters in Y. lipolytica are not as strictly controlled as in $S$. cerevisiae [42]. The strongest signal from YHT1 at C/N 20 was 
detected when $Y$. lipolytica was grown in the presence of glucose. A different situation occurred at $\mathrm{C} / \mathrm{N} 40$, where the highest expression level was achieved in a mixed cultivation. This contrasts with the previous study, in which YHT1 was not much affected by the carbon source, however, the cultivations were carried out in carbon-limiting conditions [23]. On the other hand, the upregulation of YHT4 on glycerol at C/N 40 was observed, a result similar to the IBT strain [23]. Notably, expression of 10 other genes encoding proteins belonging to SP family was detected (Fig. 5A). In this group, two, namely YALIOC04730g and YALIOD01111g showed an interesting expression pattern - they are expressed almost exclusively at low nitrogen concentration ( $C / N$ 40). The YALIOC04730g seems to be also upregulated/derepressed by glucose. During identification and characterization of hexose transporters in Y. lipolytica there were some evidences of this gene to be fructose transporter, however, the obtained results were inconclusive [41 and Lazar personal communication]. The results presented here show that regulation of substrate uptake depends not only on the presence of carbon source but also on the nitrogen availability and that additional sugar transporters might be functional in $Y$. lipolytica at higher $\mathrm{C} / \mathrm{N}$ ratio.

In Y. lipolytica the glycerol transport into the cell likely occurs via aquaglyceroporin which is an ortholog of S. cerevisiae Fps1 or a glycerol/ $\mathrm{H}^{+}$-symporter encoded by a gene orthologous to STL1. We observed a very weak expression of STL1, but the expression levels of gene encoding Fps1 (YlFPS1, YALIOF00462g) was the highest on glycerol (at C/N 40) confirming importance of this transporter for glycerol uptake. This result correlates with the recent study [23], where expression of YIFPS1 was strongly induced by glycerol but also present, when the yeast grew on glucose and a blend of glucose and glycerol. Until now, no in-depth study on the YlFps1 has been conducted, but evidence for its glycerol transporting activity was assessed in an experiment to improve glycerol consumption in S. cerevisiae [43]. Altogether, the expression data suggests that YlFps1 could be a major glycerol facilitator in $Y$. lipolytica.

Upon the uptake, glucose and glycerol are subsequently phosphorylated by kinases, what allows for their incorporation into the central carbon metabolism. Glycerol in Y. lipolytica is assimilated via the glycerol-3-phosphate (G3P) pathway, of which YlGut1 is a glycerol kinase $[37,43]$. The expression of GUT1 was higher in presence of glycerol at $\mathrm{C} / \mathrm{N} 40$ but remained constant at $\mathrm{C} /$ $\mathrm{N} 20$ regardless of the carbon source used and its expression was the highest compared to the other components of the G3P pathway, namely GUT2 and GPD1. This observation correlates with previous reports $[23,44]$. Alongside the G3P pathway, a presence of a putative catabolic DHA pathway for glycerol uptake in Y. lipolytica is still under consideration. This two-step pathway consists of an unidentified glycerol dehydrogenase and a dihydroxyacetone kinase [37,43]. Expression of genes putatively related to this pathway was detected, where the $D A K 2$, a dihydroxyacetone kinase ortholog, expression was the strongest. This contrasts with another transcriptomic study conducted in carbon-limiting conditions [23], where two DAK genes showed similar expression, while one was significantly lower expressed compared to the others.

Glucose in $Y$. lipolytica is phosphorylated by a glucokinase (YlGlk1) and a hexokinase (YlHxk1), which phosphorylates also fructose [45,46]. The GLK1 gene, encoding glucokinase, was expressed in a constant manner across all tested conditions, while surprisingly, HXK1 gene encoding hexokinase, showed very strong expression at C/N 40 (Fig. 5C). This could explain a higher specific glucose utilization rate (Table 3 ), suggesting higher flux of carbon through glycolysis. That could also be seen at the expression levels of PFK1 at $\mathrm{C} / \mathrm{N}$ 40. However, such drastic differences in HXK1 expression and similar transcript levels in various carbon source conditions suggest that hexokinase in Y. lipolytica may contribute to other cellular processes. Alongside its catalytic functions, it is well known that in S. cerevisiae hexokinase $2(\mathrm{Hxk} 2)$ plays a pivotal role in the carbon catabolite repression phenomenon [47], being a component of a Snf1/Mig1 pathway [48]. The unusual behaviour of YlHxk1 may stem from its peculiar structure, as 40 amino acid loop of unidentified function is present in its sequence [46]. This could indicate an as yet to be elucidated regulatory mechanism in which the $Y l H x k 1$ protein is an important component.

As Y. lipolytica is well suited for overproduction of Krebs cycle intermediates such as citric acid [4] we were interested to see differences in expression of genes encoding this pathway. As it turned out some of the genes have been upregulated at $\mathrm{C} / \mathrm{N} 40$, with the PYC1 being the most significant example, alongside CIT2, ACO1 and FUM1 (Fig. 5E). It is generally known, that when $Y$. lipolytica is cultivated at low nitrogen concentration a higher flux through TCA occurs leading to overproduction of some of TCA intermediates such as citric acid $[3,4]$ what could explain these results. The expression levels of CIT2 and FUM1 were the highest in presence of glycerol regardless of $\mathrm{C} / \mathrm{N}$, confirming that glycerol is a good substrate to use for overproduction of various TCA acids. Moreover, we observed that during cultivation on glucose ACO1 was more strongly expressed than CIT2 while the opposite situation took place on glycerol (Fig. 5E). From these findings we hypothesize that when using glucose as sole carbon source $Y$. lipolytica is rather set for growth, while glycerol utilization causes overproduction of citric acid. This could also explain high citric to isocitric ratios (high purity of citric acid) in the A101 strain and its derivatives $[6,49,50]$. A relatively lower flux through the pentose phosphate pathway upon growth on glycerol in contrast to glucose could also contribute to the overproduction of citric acid, as it is feasible that insufficient NADPH precludes the formation of storage lipids.

Apart from citric acid, Y. lipolytica has been developed as a promising host for erythritol biosynthesis, especially from glycerol [6,51], therefore, we were interested to check the expression levels of the erythritol biosynthesis pathway encoding genes. The genes involved in erythritol biosynthesis were generally similarly expressed, however, four genes, namely TAL1,GCY15, ARA12 and GRE3 exhibited interesting expression patterns at C/N 40. TAL1 (YALIOF15587g) encodes a transaldolase while GCY15 (YALIOF18590g), ARA12 (YALIOC13508g) and GRE3 (YALIOD07634g) encode erythrose reductases [52,53]. Their transcript levels were almost the same when cultured on glycerol and a blend of glycerol and glucose but approximately two-fold lower when cultured on glucose alone, proving that glycerol is a well suited carbon source for production of erythritol. Additionally, the expression data for erythritol biosynthesis pathway suggests that production of this polyol in Y. lipolytica might be improved by cultivation in higher nitrogen concentrations, however, this does not correlate with current methods in which high $\mathrm{C} / \mathrm{N}$ ratios (typically $\mathrm{C} / \mathrm{N} 70$ ) are used [51,54,55].

The same expression pattern as for TAL1, GCY15, ARA1 and, GRE3 was observed for other genes not directly related to erythritol biosynthesis, namely DAK2,IDH1, IDH2 and ICL1. Additionally, on glucose at $\mathrm{C} / \mathrm{N} 20$ their expression was noticeably higher than at $\mathrm{C} /$ $\mathrm{N} 40$. We were interested to elucidate this pattern with very high expression of hexokinase at $\mathrm{C} / \mathrm{N} 40$, so we used a hexokinase overexpressing strain to check for transcript levels of the above genes. Indeed, a clear impact of more highly expressed hexokinase could be observed for GCY15, IDH1 and IDH2, as their expression levels at C/N 40 matched that of a wild-type at C/N 20. There is an evidence of HXK1 involvement in glucose catabolite repression of the LIP2 gene encoding extracellular lipase in Y. lipolytica [56]. Taken together, it is feasible that HXK1 is an element of a gene regulatory network, or acts in concert with other parts in a transcription controlling machinery, in which expression of genes 
depends on the hexokinase abundance. However, this hypothesis should be tested in more detail.

As HXK1 was strongly upregulated at $\mathrm{C} / \mathrm{N} 40$ we were curious if any of the analyzed genes showed similarity to the HXK1 expression pattern, as often genes with similar expression profiles share common transcription factors. Two genes encoding proteins belonging to the SP family, namely YALIOC04730 $g$ and YALIOD01111 $g$, were chosen due to strong expression at C/N 40 (Fig. 7). The analysis of promoter sequences revealed that motifs recognized by Gat 1 and Gzf3 zinc-finger protein homologues are present. Both of the proteins are GATA-type transcription factors in S. cerevisiae, and while Gat 1 acts as an activator for nitrogen utilization genes in poor nitrogen conditions [57], Gzf3 act as a repressor competing for binding sites with Gat1 [58,59]. This is puzzling since HXK1, YALIOC04730 $\mathrm{g}$ and YALIOD01111 $\mathrm{g}$ are not directly implicated in nitrogen metabolism but in the metabolism of carbon sources. However, with the data presented here one could assume, that these genes are upregulated by Gat1-like transcription factor in poor nitrogen conditions (e.g. C/N 40) and downregulated by Gzf3, when more nitrogen is available (e.g. C/N20). It will be of great importance for the development of $Y$. lipolytica as even more robust cell factory to analyze these interactions closer.

\section{Conclusions}

The present study focused on elucidating the molecular background of the unique glucose and glycerol utilization pattern in the yeast $Y$. lipolytica and an influence of the interplay between carbon sources and carbon to nitrogen ratios on the global gene expression using RNAseq based transcriptomics. The results show that glycerol is used prior to glucose regardless nitrogen availability and that $\mathrm{C} / \mathrm{N}$ ratio is a stronger factor influencing gene expression than carbon source. The major finding of this work is that hexokinase (HXK1) expression is highly dependent on nitrogen concentration as at high $\mathrm{C} / \mathrm{N}$ its expression levels were drastically elevated compared to low $\mathrm{C} / \mathrm{N}$ ratio. Furthermore, we show that HXK1 expression in Y. lipolytica could be controlled via GATA zinc-finger transcription factors and that hexokinase itself could influence expression of certain genes through an as yet to be discovered mechanism.

\section{Auhtor statement}

PH designed the experiment, performed the experiments, wrote the manuscript, EJK designed the experiments, supervised transcriptome analysis, revised the manuscript, ZL designed the experiments, revised the manuscript.

\section{Funding}

PH acknowledges funding from EMBO (Short-term Fellowship no. 7499) and Wroclaw University of Environmental and Life Sciences ("Innowacyjny Doktorat", grant no. D220/0006/17). EJK acknowledges funding from FORMAS (2018-00597). ZL acknowledges funding from National Science Center ("Miniatura 2", grant no. 2018/02/X/NZ9/00591).

\section{Declaration of Competing Interest}

None.

\section{Acknowledgements}

The authors would like to thank Dr. Magdalena RakickaPustułka and Dr. Heber Gamboa-Melendez for critical comments on the final version of the manuscript.

\section{Appendix A. Supplementary data}

Supplementary material related to this article can be found, in the online version, at doi:https://doi.org/10.1016/j.btre.2020. e00521.

\section{References}

[1] M. Fayyad-Kazan, A. Feller, E. Bodo, M. Boeckstaens, A.M. Marini, E. Dubois, I. Georis, Yeast nitrogen catabolite repression is sustained by signals distinct from glutamine and glutamate reservoirs, Mol. Microbiol. 99 (2) (2016) 360379.

[2] K. Simpson-Lavy, M. Kupiec, Carbon catabolite repression in yeast is not limited to glucose, Sci. Rep. 9 (1) (2019) 1-10.

[3] S. Papanikolaou, G. Aggelis, Biotechnological valorization of biodiesel derived glycerol waste through production of single cell oil and citric acid by Yarrowia lipolytica, Lipid Technol. 21 (4) (2009) 83-87.

[4] W. Rymowicz, A.R. Fatykhova, S.V. Kamzolova, A. Rywińska, I.G. Morgunov, Citric acid production from glycerol-containing waste of biodiesel industry by Yarrowia lipolytica in batch, repeated batch, and cell recycle regimes, Appl. Microbiol. Biotechnol. 87 (3) (2010) 971-979.

[5] J. Zhou, X. Yin, C. Madzak, G. Du, J. Chen, Enhanced $\alpha$-ketoglutarate production in Yarrowia lipolytica WSH-Z06 by alteration of the acetyl-CoA metabolism, J. Biotechnol. 161 (3) (2012) 257-264.

[6] M. Rakicka, B. Rukowicz, A. Rywińska, Z. Lazar, W. Rymowicz, Technology of efficient continuous erythritol production from glycerol, J. Clean. Prod. 139 (2016) 905-913.

[7] L. Tomaszewska, A. Rywińska, W. Gładkowski, Production of erythritol and mannitol by Yarrowia lipolytica yeast in media containing glycerol, J. Ind. Microbiol. Biotechnol. 39 (9) (2012) 1333-1343.

[8] Y. Waché, M. Aguedo, A. Choquet, I.L. Gatfield, J.M. Nicaud, J.M. Belin, Role of $\beta$ oxidation enzymes in $\gamma$-decalactone production by the yeast Yarrowia lipolytica, Appl. Environ. Microbiol. 67 (12) (2001) 5700-5704.

[9] C. Madzak, Yarrowia lipolytica: recent achievements in heterologous protein expression and pathway engineering, Appl. Microbiol. Biotechnol. 99 (11) (2015) 4559-4577.

[10] G. Barth, C. Gaillardin, Yarrowia lipolytica, Nonconventional Yeasts in Biotechnology, Springer, Berlin, Heidelberg, 1996, pp. 313-388.

[11] K. De Pourcq, W. Vervecken, I. Dewerte, A. Valevska, A. Van Hecke, N Callewaert, Engineering the yeast Yarrowia lipolytica for the production of therapeutic proteins homogeneously glycosylated with Man 8 GlcNAc 2 and Man 5 GlcNAc 2, Microb. Cell Fact. 11 (1) (2012) 53.

[12] J.M. Nicaud, Yarrowia lipolytica, Yeast 29 (10) (2012) 409-418.

[13] A. André, A. Chatzifragkou, P. Diamantopoulou, D. Sarris, A. Philippoussis, M. Galiotou-Panayotou, S. Papanikolaou, Biotechnological conversions of biodiesel-derived crude glycerol by Yarrowia lipolytica strains, Eng. Life Sci. 9 (6) (2009) 468-478.

[14] C. Holkenbrink, M.I. Dam, K.R. Kildegaard, J. Beder, J. Dahlin, D. Doménech Belda, I. Borodina, EasyCloneYALI: CRISPR/Cas9-based synthetic toolbox for engineering of the yeast Yarrowia lipolytica, Biotechnol. J. 13 (9) (2018) 1700543.

[15] M. Larroude, Y.K. Park, P. Soudier, M. Kubiak, J.M. Nicaud, T. Rossignol, A modular Golden Gate toolkit for Yarrowia lipolytica synthetic biology, Microb. Biotechnol. 12 (6) (2019) 1249-1259.

[16] C.M. Schwartz, M.S. Hussain, M. Blenner, I. Wheeldon, Synthetic RNA polymerase III promoters facilitate high-efficiency CRISPR-Cas9-mediated genome editing in Yarrowia lipolytica, ACS Synth. Biol. 5 (4) (2016) 356-359.

[17] P. Fickers, P.H. Benetti, Y. Waché, A. Marty, S. Mauersberger, M.S. Smit, J.M. Nicaud, Hydrophobic substrate utilisation by the yeast Yarrowia lipolytica, and its potential applications, FEMS Yeast Res. 5 (6-7) (2005) 527-543.

[18] S. Papanikolaou, A. Chatzifragkou, S. Fakas, M. Galiotou-Panayotou, M. Komaitis, J.M. Nicaud, G. Aggelis, Biosynthesis of lipids and organic acids by Yarrowia lipolytica strains cultivated on glucose, Eur. J. Lipid Sci. Technol. 111 (12) (2009) 1221-1232.

[19] J.R. Almeida, L.C. Fávaro, B.F. Quirino, Biodiesel biorefinery: opportunities and challenges for microbial production of fuels and chemicals from glycerol waste, Biotechnol. Biofuels 5 (1) (2012) 48.

[20] A. Chatzifragkou, S. Papanikolaou, Effect of impurities in biodiesel-derived waste glycerol on the performance and feasibility of biotechnological processes, Appl. Microbiol. Biotechnol. 95 (1) (2012) 13-27.

[21] M. Workman, P. Holt, J. Thykaer, Comparing cellular performance of Yarrowia lipolytica during growth on glucose and glycerol in submerged cultivations, AMB Express 3 (1) (2013) 58.

[22] A. Rywińska, W. Rymowicz, B. Żarowska, A. Skrzypiński, Comparison of citric acid production from glycerol and glucose by different strains of Yarrowia lipolytica, World J. Microbiol. Biotechnol. 26 (7) (2010) 1217-1224.

[23] P. Lubuta, M. Workman, E.J. Kerkhoven, C.T. Workman, Investigating the influence of glycerol on the utilization of glucose in Yarrowia lipolytica using RNA-Seq-Based transcriptomics, G3 Genes| Genomes| Genet. 9 (12) (2019) 4059-4071.

[24] M. Wojtatowicz, W. Rymowicz, Effect of Inoculum on Kinetics and Yield of Citric Acid Production on Glucose Media by Yarrowia Lipolytica A-101 Acta Alimentaria Polonica (Poland), (1991) . 
[25] S. Andrews, Babraham bioinformatics-FastQC a Quality Control Tool for High Throughput Sequence Data (accessed 04.11.2019)URL:, (2010) . https://www. bioinformatics.babraham.ac.uk/projects/fastqc/.

[26] A.M. Bolger, M. Lohse, B. Usadel, Trimmomatic: a flexible trimmer for Illumina sequence data, Bioinformatics 30 (15) (2014) 2114-2120.

[27] A. Dobin, C.A. Davis, F. Schlesinger, J. Drenkow, C. Zaleski, S. Jha, T.R. Gingeras STAR: ultrafast universal RNA-seq aligner, Bioinformatics 29 (1) (2013) 15-21.

[28] Y. Liao, G.K. Smyth, W. Shi, The Subread aligner: fast, accurate and scalable read mapping by seed-and-vote, Nucleic Acids Res. 41 (10) (2013) e108-e108.

[29] S. Anders, W. Huber, Differential expression analysis for sequence count data, Nat. Preced. (2010) 1-1.

[30] P.T. Monteiro, J. Oliveira, P. Pais, M. Antunes, M. Palma, M. Cavalheiro, M.N. Mota, YEASTRACT+: a portal for cross-species comparative genomics of transcription regulation in yeasts, Nucleic Acids Res. 48 (D1) (2020) D642D649.

[31] M. Kanehisa, S. Goto, KEGG: Kyoto Encyclopedia of Genes and Genomes, Nucleic Acids Res. 28 (2000) 27-30.

[32] A. Beopoulos, J. Cescut, R. Haddouche, J.L. Uribelarrea, C. Molina-Jouve, J.M. Nicaud, Yarrowia lipolytica as a model for bio-oil production, Prog. Lipid Res. 48 (6) (2009) 375-387.

[33] I.G. Morgunov, S.V. Kamzolova, J.N. Lunina, The citric acid production from raw glycerol by Yarrowia lipolytica yeast and its regulation, Appl. Microbiol. Biotechnol. 97 (16) (2013) 7387-7397.

[34] P. Juszczyk, L. Tomaszewska, A. Kita, W. Rymowicz, Biomass production by novel strains of Yarrowia lipolytica using raw glycerol, derived from biodiesel production, Bioresour. Technol. 137 (2013) 124-131.

[35] N. Morin, J. Cescut, A. Beopoulos, G. Lelandais, V. Le Berre, J.L. Uribelarrea, J.M. Nicaud, Transcriptomic analyses during the transition from biomass production to lipid accumulation in the oleaginous yeast Yarrowia lipolytica, PLoS One 6 (11) (2011).

[36] S. Papanikolaou, G. Aggelis, Lipid production by Yarrowia lipolytica growing on industrial glycerol in a single-stage continuous culture, Bioresour. Technol. 82 (1) (2002) 43-49.

[37] T. Dulermo, J.M. Nicaud, Involvement of the G3P shuttle and $\beta$-oxidation pathway in the control of TAG synthesis and lipid accumulation in Yarrowia lipolytica, Metab. Eng. 13 (5) (2011) 482-491.

[38] K.E. Sherwood, D.J. Cano, J.A. Maupin-Furlow, Glycerol-mediated repression of glucose metabolism and glycerol kinase as the sole route of glycerol catabolism in the haloarchaeon Haloferax volcanii, J. Bacteriol. 191 (13) (2009) 4307-4315.

[39] K. Mori, R. Iwama, S. Kobayashi, H. Horiuchi, R. Fukuda, A. Ohta, Transcriptional repression by glycerol of genes involved in the assimilation of n-alkanes and fatty acids in yeast Yarrowia lipolytica, FEMS Yeast Res. 13 (2) (2013) 233-240.

[40] G. Bhutada, M. Kavšček, R. Ledesma-Amaro, S. Thomas, G.N. Rechberger, J.M. Nicaud, K. Natter, Sugar versus fat: elimination of glycogen storage improves lipid accumulation in Yarrowia lipolytica, FEMS Yeast Res. 17 (3) (2017).

[41] Z. Lazar, C. Neuvéglise, T. Rossignol, H. Devillers, N. Morin, M. Robak, A.M Crutz-Le Coq, Characterization of hexose transporters in Yarrowia lipolytica reveals new groups of sugar porters involved in yeast growth, Fungal Genet. Biol. 100 (2017) 1-12.

[42] Ö. Kayikci, J. Nielsen, Glucose repression in Saccharomyces cerevisiae, FEMS Yeast Res. 15 (6) (2015) fov068.
[43] M. Klein, Z.U. Islam, P.B. Knudsen, M. Carrillo, S. Swinnen, M. Workman, E. Nevoigt, The expression of glycerol facilitators from various yeast species improves growth on glycerol of Saccharomyces cerevisiae, Metab. Eng. Commun. 3 (2016) 252-257.

[44] A. Makri, S. Fakas, G. Aggelis, Metabolic activities of biotechnological interest in Yarrowia lipolytica grown on glycerol in repeated batch cultures, Bioresour. Technol. 101 (7) (2010) 2351-2358.

[45] Z. Lazar, T. Dulermo, C. Neuvéglise, A.M. Crutz-Le Coq, J.M. Nicaud, Hexokinase-a limiting factor in lipid production from fructose in Yarrowia lipolytica, Metab. Eng. 26 (2014) 89-99.

[46] T. Petit, C. Gancedo, Molecular cloning and characterization of the gene HXK1 encoding the hexokinase from Yarrowia lipolytica, Yeast 15 (15) (1999) 15731584.

[47] J.M. Gancedo, Yeast carbon catabolite repression, Microbiol. Mol. Biol. Rev. 62 (2) (1998) 334-361.

[48] M. Conrad, J. Schothorst, H.N. Kankipati, G. Van Zeebroeck, M. Rubio-Texeira, J. M. Thevelein, Nutrient sensing and signaling in the yeast Saccharomyces cerevisiae, FEMS Microbiol. Rev. 38 (2) (2014) 254-299.

[49] W. Rymowicz, A. Rywińska, B. Żarowska, P. Juszczyk, Citric acid production from raw glycerol by acetate mutants of Yarrowia lipolytica, Chem. Pap. 60 (5) (2006) 391-394.

[50] D.A. Rzechonek, A. Dobrowolski, W. Rymowicz, A.M. Mirończuk, Aseptic production of citric and isocitric acid from crude glycerol by genetically modified Yarrowia lipolytica, Bioresour. Technol. 271 (2019) 340-344.

[51] F. Carly, M. Vandermies, S. Telek, S. Steels, S. Thomas, J.M. Nicaud, P. Fickers, Enhancing erythritol productivity in Yarrowia lipolytica using metabolic engineering, Metab. Eng. 42 (2017) 19-24.

[52] T. Janek, A. Dobrowolski, A. Biegalska, A.M. Mirończuk, Characterization of erythrose reductase from Yarrowia lipolytica and its influence on erythritol synthesis, Microb. Cell Fact. 16 (1) (2017) 118.

[53] H. Cheng, S. Wang, M. Bilal, X. Ge, C. Zhang, P. Fickers, H. Cheng, Identification, characterization of two NADPH-dependent erythrose reductases in the yeast Yarrowia lipolytica and improvement of erythritol productivity using metabolic engineering, Microb. Cell Fact. 17 (1) (2018) 133.

[54] A.M. Mirończuk, A. Biegalska, A. Dobrowolski, Functional overexpression of genes involved in erythritol synthesis in the yeast Yarrowia lipolytica, Biotechnol. Biofuels 10 (1) (2017) 77.

[55] W. Rymowicz, A. Rywińska, M. Marcinkiewicz, High-yield production of erythritol from raw glycerol in fed-batch cultures of Yarrowia lipolytica, Biotechnol. Lett. 31 (3) (2009) 377-380.

[56] P. Fickers, J.M. Nicaud, J. Destain, P. Thonart, Involvement of hexokinase Hxk1 in glucose catabolite repression of LIP2 encoding extracellular lipase in the yeast Yarrowia lipolytica, Curr. Microbiol. 50 (3) (2005) 133-137.

[57] I. Georis, A. Feller, F. Vierendeels, E. Dubois, The yeast GATA factor Gat1 occupies a central position in nitrogen catabolite repression-sensitive gene activation, Mol. Cell. Biol. 29 (13) (2009) 3803-3815.

[58] K.R. Pomraning, E.L. Bredeweg, S.E. Baker, Regulation of nitrogen metabolism by GATA zinc finger transcription factors in Yarrowia lipolytica, mSphere 2 (1) (2017) e00038-17.

[59] S. Soussi-Boudekou, S. Vissers, A. Urrestarazu, J.C. Jauniaux, B. André, Gzf3p, a fourth GATA factor involved in nitrogen-regulated transcription in Saccharomyces cerevisiae, Mol. Microbiol. 23 (6) (1997) 1157-1168. 